\title{
Erratum to: Molecular phylogeny of the subfamily Stevardiinae Gill, 1858 (Characiformes: Characidae): classification and the evolution of reproductive traits
}

Andréa T. Thomaz ${ }^{1,2+}$, Dahiana Arcila ${ }^{3,4 \dagger}$, Guillermo Ortî ${ }^{3}$ and Luiz R. Malabarba ${ }^{2^{*}}$

\section{Erratum}

The original version of this article unfortunately contained some mistakes. The presentation of Figs. 3-10 were incorrect in the HTML and PDF versions of this article. The corrected figures are given below. In addition, Additional file 4 and 5 were presented incorrectly. The updated versions of these files are also supplied below.

\footnotetext{
* Correspondence: malabarb@ufrgs.br

${ }^{\dagger}$ Equal contributors

${ }^{2}$ Departamento de Zoologia, Universidade Federal do Rio Grande do Sul

(UFRGS), Av. Bento Gonçalves 9500, Porto Alegre 90501-970, RS, Brazil

Full list of author information is available at the end of the article
} 


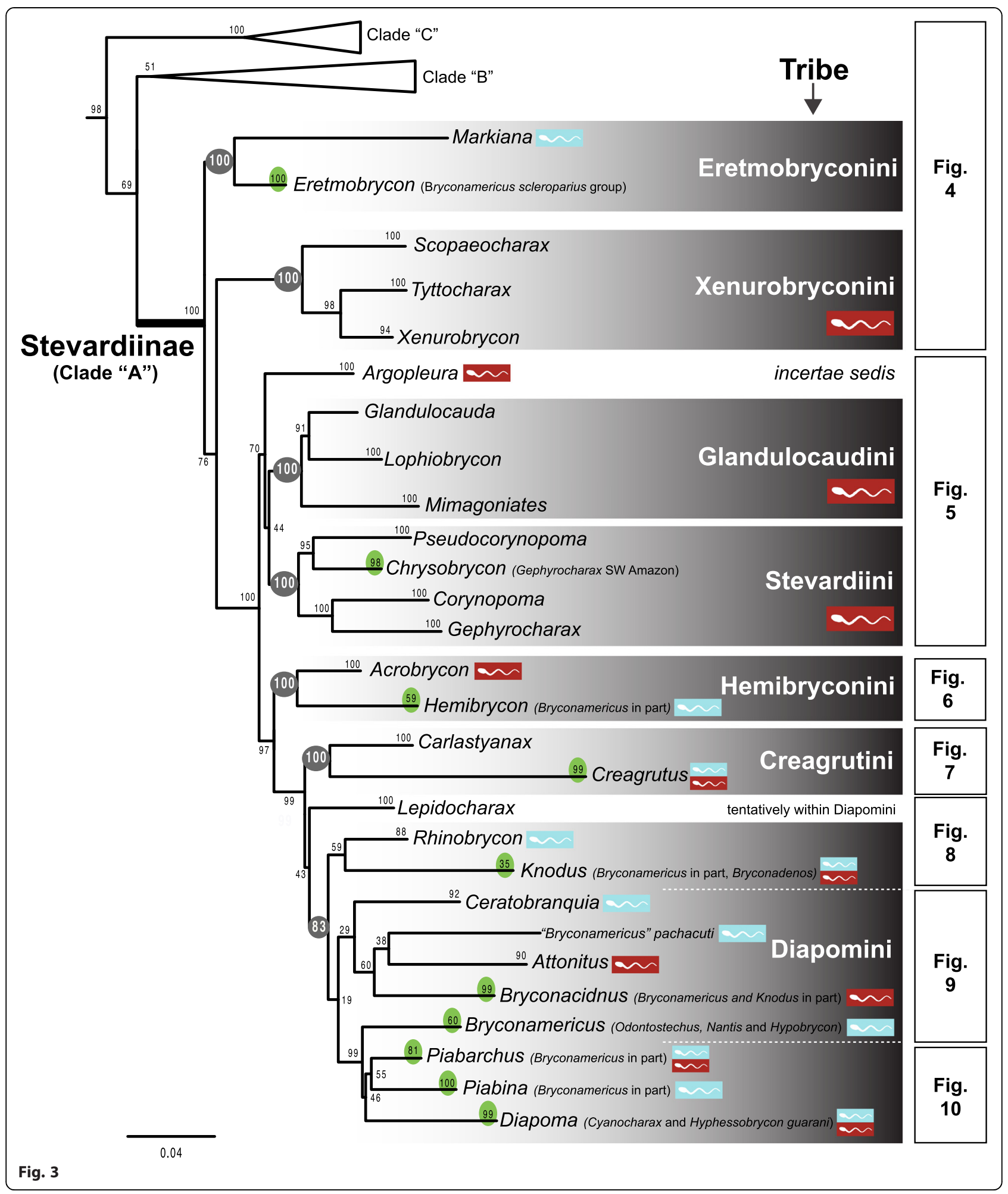




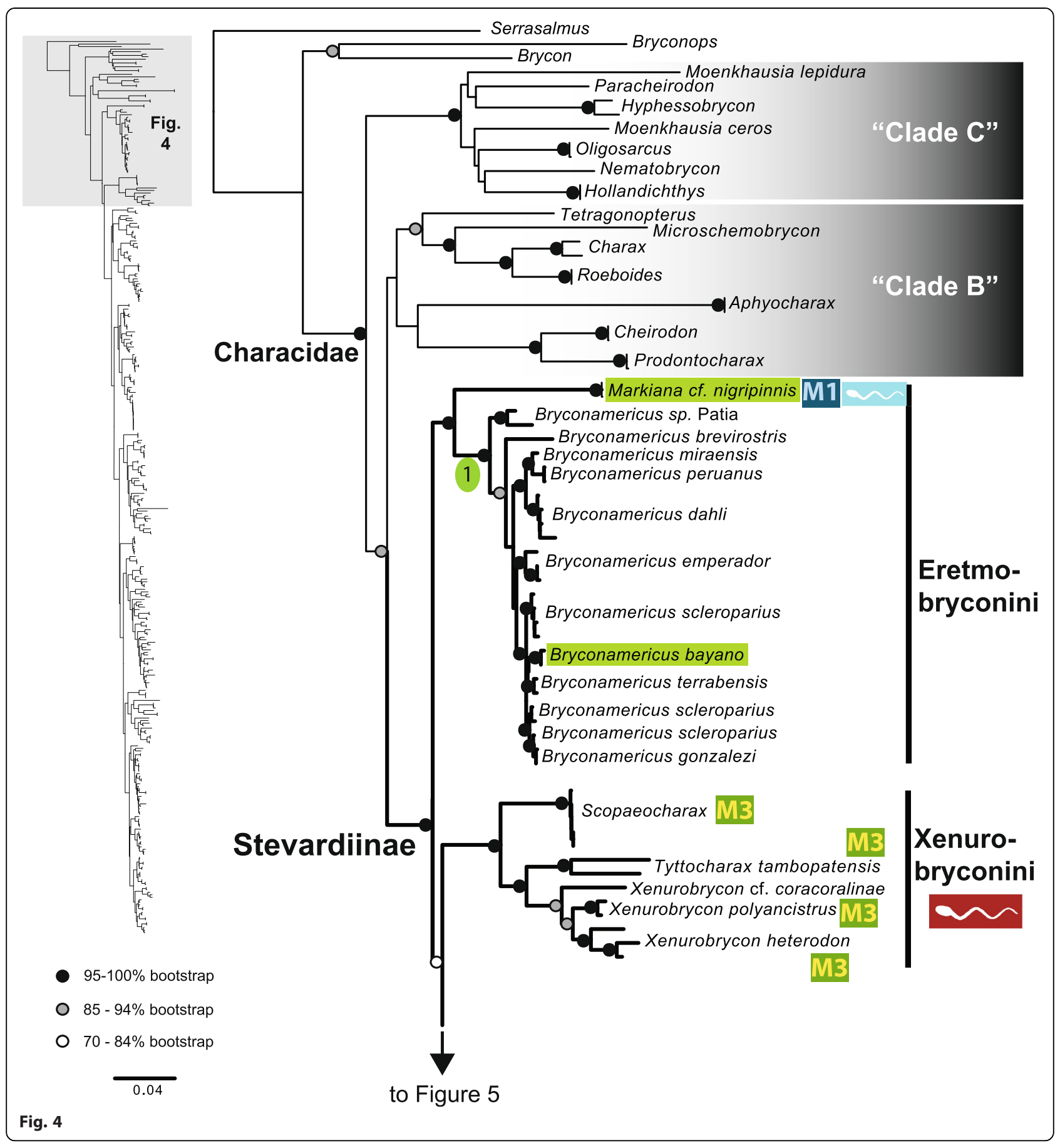




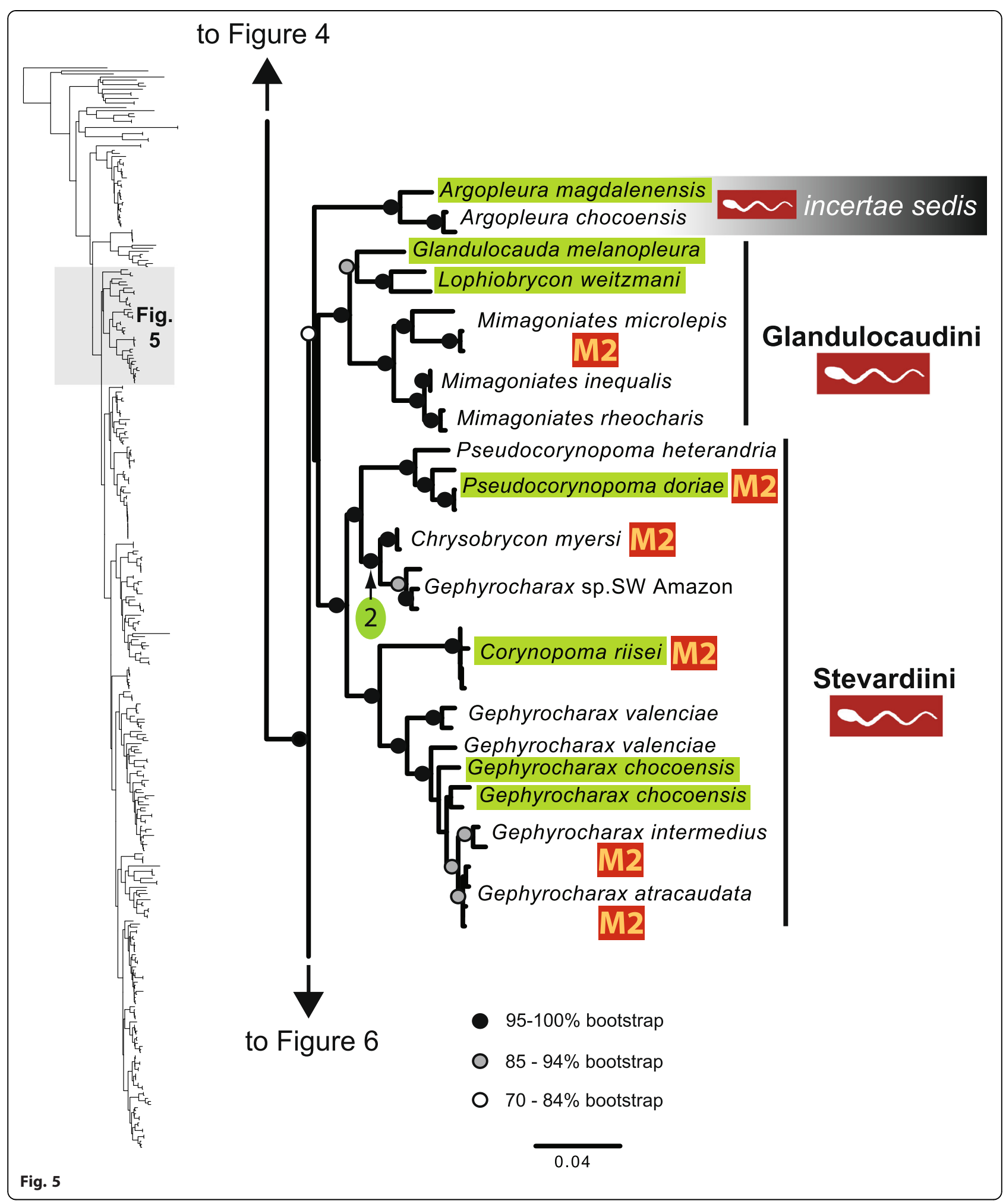




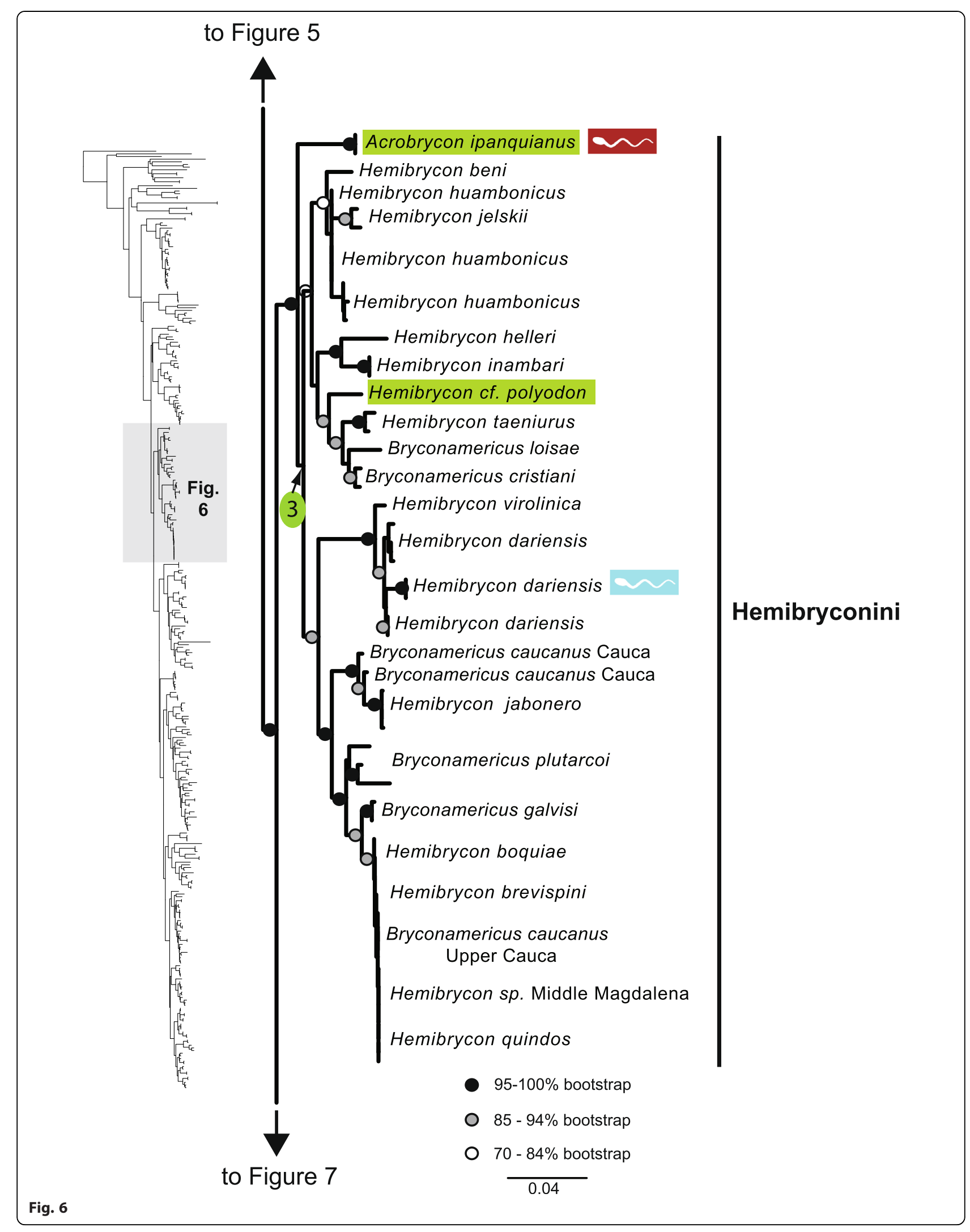




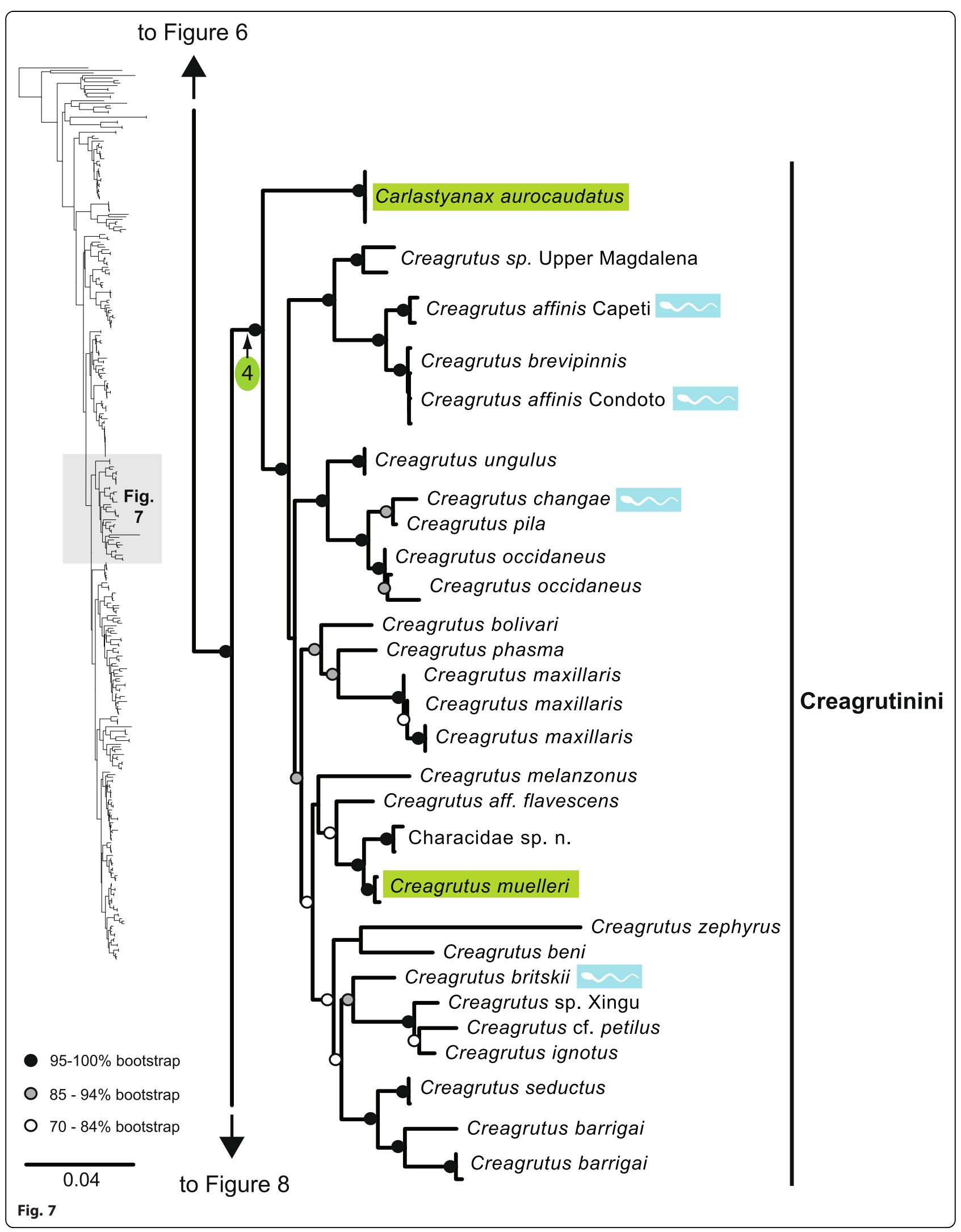




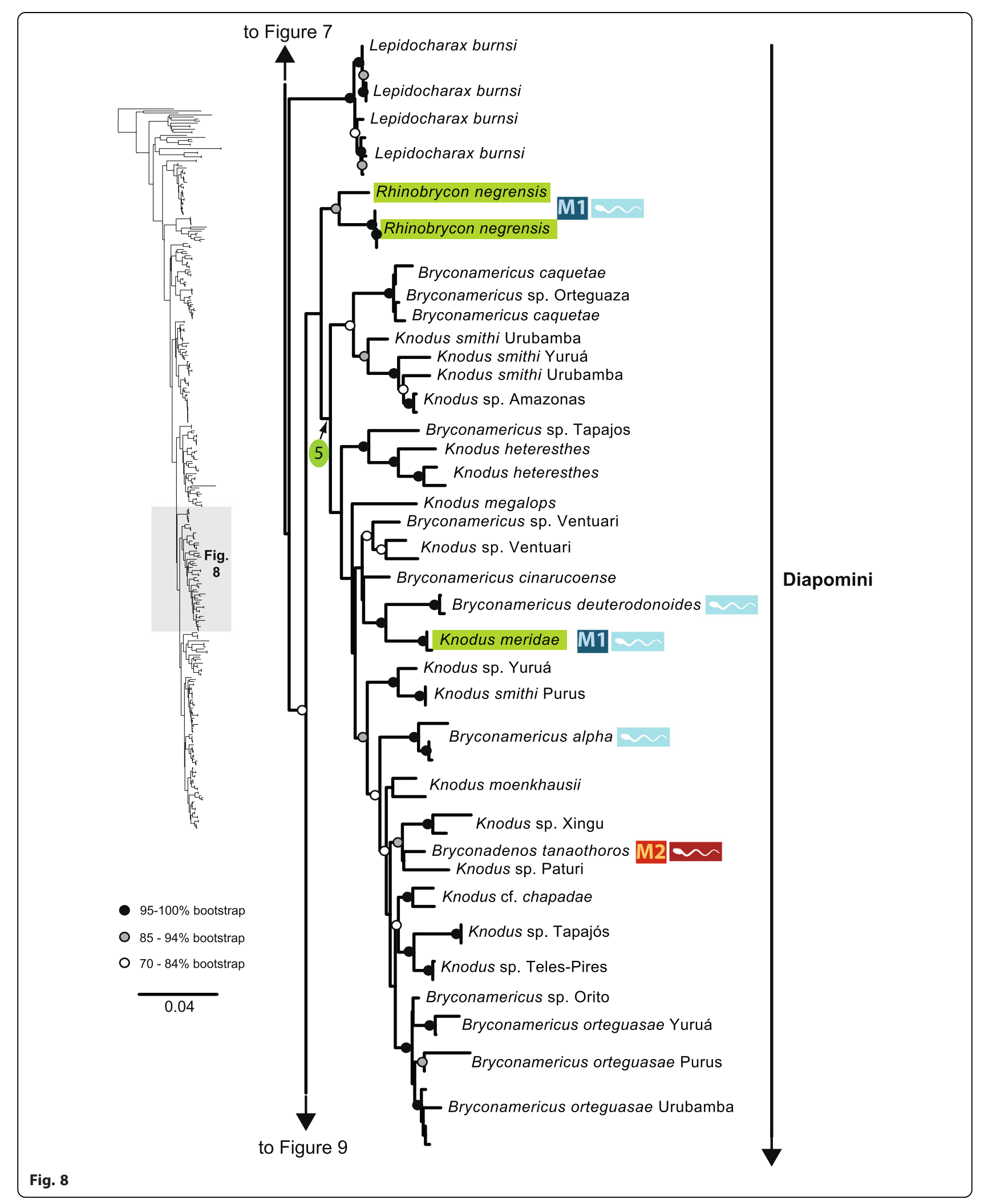




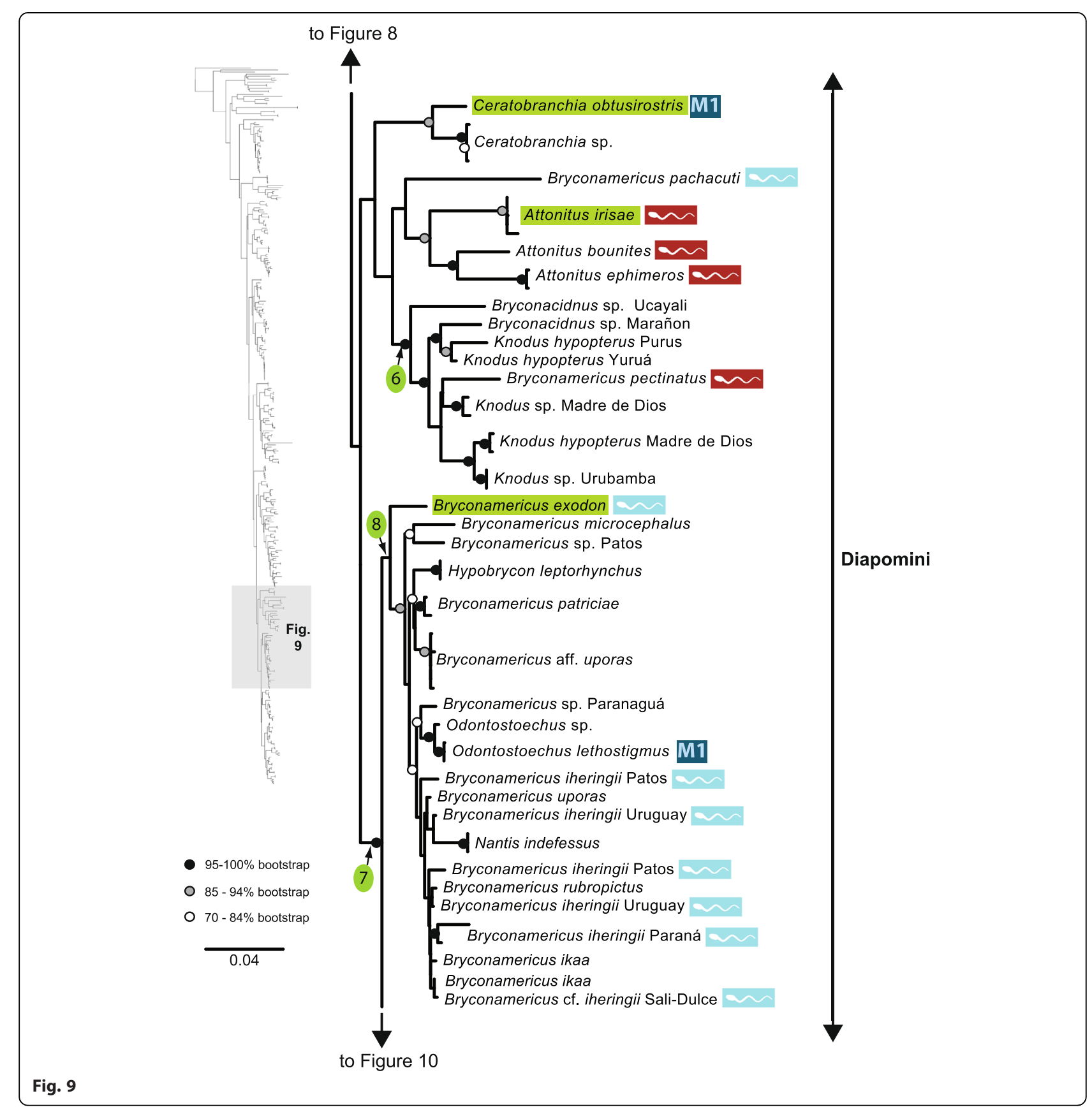




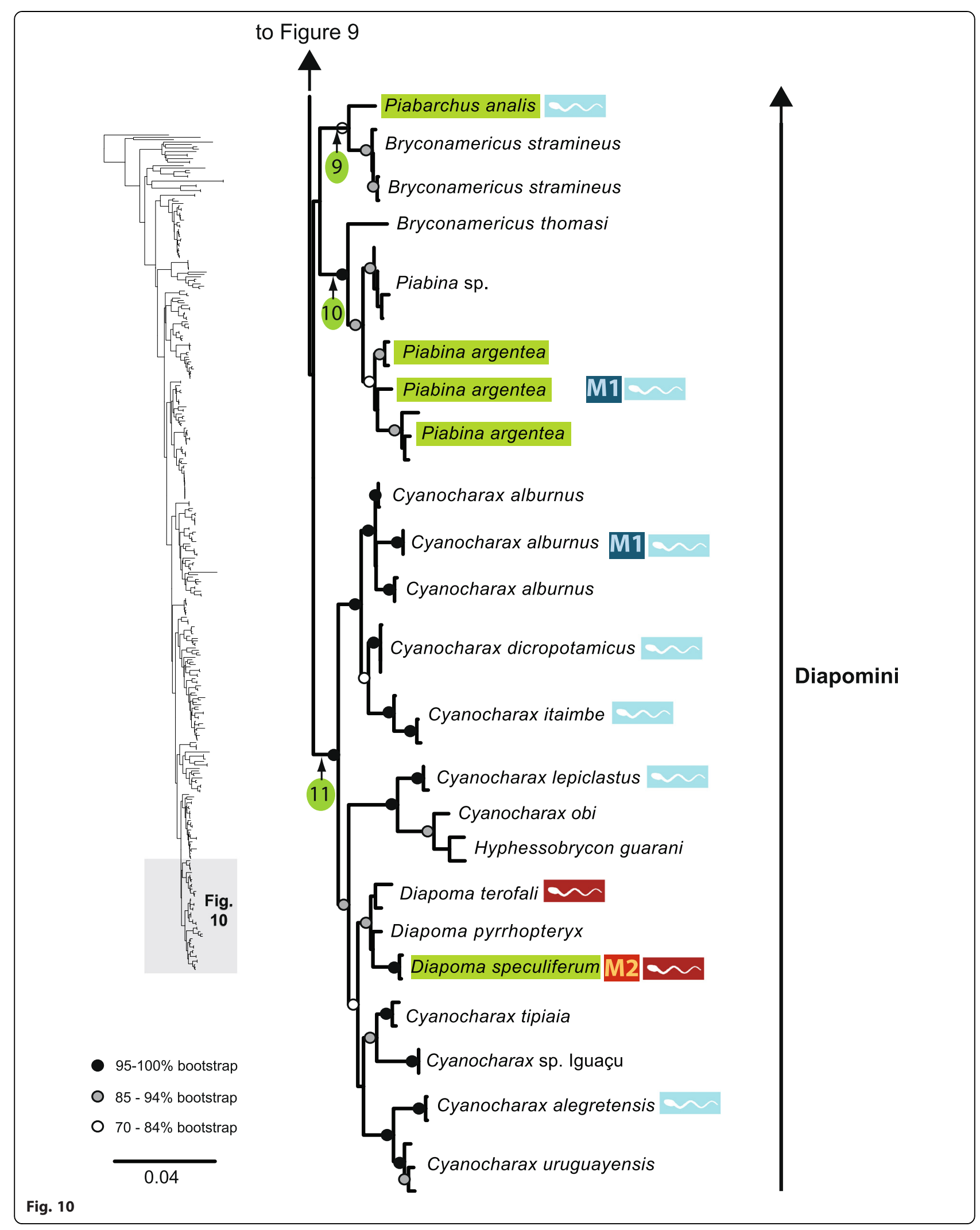




\section{Additional files}

Additional file 4: Unabridged ML tree obtained with RAxML. Labels correspond to specimens listed in Additional file 2. Bootstrap values (\%) are placed next to internal branches. Sections of the phylogeny presented in Figures 4 to 10 are marked.

(PDF $687 \mathrm{~kb}$ )

Additional file 5: New Stevardiinae classification. New classification of the subfamily Stevardiinae based on phylogenetic relationships proposed herein (Figures 4-10 is summarized in Figure 3 in the original manuscript). Taxa not examined in the current study are tentatively assigned to tribes and genera based on previous studies (see discussion for details). T: denotes the type species of the genus. [NC]: species assigned to a different genus (NEW COMBINATION). (DOCX $130 \mathrm{~kb}$ )

\section{Author details}

'Department of Ecology and Evolutionary Biology (EEB), University of Michigan, 1109 Geddes Ave., Ann Arbor 48109, MI, USA. ${ }^{2}$ Departamento de Zoologia, Universidade Federal do Rio Grande do Sul (UFRGS), Av. Bento Gonçalves 9500, Porto Alegre 90501-970, RS, Brazil. ${ }^{3}$ Department of Biological Sciences, The George Washington University, 2023 G St. NW, Washington 20052, DC, USA. ${ }^{4}$ Department of Vertebrate Zoology, National Museum of Natural History Smithsonian Institution, MRC 159, Washington 20013, DC, USA.

Published online: 03 December 2015

\section{Reference}

1. Thomaz AT, Arcila D, Ortí G, Malabarba LR. BMC Evol Biol. 2015;15:146. doi:10.1186/s12862-015-0403-4.

\section{Submit your next manuscript to BioMed Central and take full advantage of:}

- Convenient online submission

- Thorough peer review

- No space constraints or color figure charges

- Immediate publication on acceptance

- Inclusion in PubMed, CAS, Scopus and Google Scholar

- Research which is freely available for redistribution 